Revista de Derecho

de la Pontificia Universidad Católica de Valparaíso

XXXI (Valparaíso, Chile, 2 Semestre de 2008)

[pp. 267 - 288]

\title{
APLICACIÓN JURISPRUDENCIAL DE LAS NUEVAS CAUSALES DE TERMINACIÓN DEL MATRIMONIO
}

[Jurisprudential Application of the New Causes of Marriage Termination]

\author{
María Soledad Quintana Villa* \\ Pontificia Universidad Católica de Valparaíso
}

\begin{abstract}
RESUMEN
Desde la publicación de la Ley de matrimonio civil es posible comprobar la existencia de disparidad de criterios sobre diversas materias y, por tanto, fallos contradictorios. En este trabajo se trata de algunos temas de interés práctico, entre ellos, la posibilidad de enervar la acción de divorcio que tiene el demandado cuando el actor ha incumplido reiteradamente la obligación alimenticia; la interposición conjunta de la solicitud de divorcio; la procedencia, o no, de indemnización por daño moral; los legitimados activos para entablar la acción de nulidad, y ciertos aspectos relativos a la compensación económica.

Palabras Clave: Incumplimiento reiterado de la obligación alimenticia Interposición conjunta de la solicitud de divorcio - Legitimados activos para entablar la acción de nulidad - Compensación económica.
\end{abstract} ABSTRACT
Ever since the publication of Civil
Matrimony Law we have been able to no-
tice the variety of criteria about different
subjects and thus, contradictory judg-
ments. This paper covers some issues of
practical interest, such as the possibility
the defendant has of detaining a divorce
lawsuit when the plaintiff has repeatedly
failed to perform child support and ali-
mony; joint divorce requirement lawsuit;
to establish whether it is appropriate
or not to indemnify on psychological
damage; who has the right to initiate
nullity action and some aspects related
to economic compensation.
KEywORDs: Repeated failure to per-
form child support and alimony - Joint
divorce requirement lawsuit - Autho-
rized plaintiffs to initiate nullity action
- Economic compensation.

* Profesora auxiliar de Derecho Civil de la Facultad de Derecho de la Pontificia Universidad Católica de Valparaíso. Dirección Postal: Facultad de Derecho, Pontificia Universidad Católica de Valparaíso, Avenida Brasil 2950, Valparaíso, Chile. Correo electrónico: msoledadquintana@gmail.com. El presente artículo ha sido escrito con la colaboración de Ana Gómez Calderón, Egresada de la Escuela de Derecho, PUCV. 


\section{INTRODUCCIÓN}

La Ley de matrimonio civil ha sido ampliamente tratada por los autores. Desde su publicación fue posible advertir que ciertas normas podían ser interpretadas en más de un sentido; por tanto, se hizo predecible que no estaría ajena a discusiones doctrinarias ni a jurisprudencia contradictoria. Constituyen una demostración fehaciente de esta afirmación los fallos tanto de tribunales de instancia como de la Corte Suprema que revisaremos en las siguientes líneas.

Asimismo, podremos constatar diversos problemas en la aplicación de la ley, lo que ha conducido a que se desestimen pretensiones justas, por no haber sido alegadas oportunamente o no haberse hecho valer a través de los recursos adecuados.

En suma, el objeto de este artículo, no es sino mostrar, a través del análisis de sentencias, la actitud que los tribunales y abogados han tenido respecto de los nuevos capítulos de terminación del matrimonio.

\section{APLICACIÓN JURISPRUDENCIAL DEL ARTÍCULO 55 INCISO $3{ }^{\circ}$. DIVORCIO REMEDIO}

En un artículo anterior ${ }^{1}$ nos referíamos a una paradoja que fue advertida en el debate parlamentario de la actual Ley de matrimonio civil. Nuestro país, después de años de ser calificado de retrógrado por no admitir el divorcio vincular, acogió esta causal de término del matrimonio en su vertiente más liberal, pues no impuso mayores requisitos para su concesión. Es así como consagró la posibilidad de demandarlo unilateralmente cuando ha existido un cese efectivo de la convivencia por un lapso no menor de tres años como una suerte de repudio del cónyuge demandante respecto del cónyuge demandado. Es tal la laxitud del legislador, en esta materia, que el cónyuge demandado solo puede enervar la acción, alegando que su comparte incumplió su obligación alimenticia respecto de él y de los hijos comunes, pudiendo hacerlo, exigiéndose, además, que dicho incumplimiento fuese reiterado, hecho que deberá ser verificado por el juez, lo que ha suscitado más de un problema de interpretación.

1. ¿Sobre quién recae el "onus probandi" respecto del cumplimiento o incumplimiento de la obligación alimenticia?

${ }^{1}$ Quintana Villar, María Soledad, La separación de hecho y el divorcio en la "Ley de matrimonio civil", en GuZMÁn BRITO, Alejandro (editor científico), Colección de estudios de Derecho Civil en homenaje a la profesora Inés Pardo de Carvallo (Valparaíso, Ediciones Universitarias de Valparaíso, 2008), pp. 91-92. 
No existiendo norma especial en la Ley de matrimonio civil, debemos aplicar la regla general del artículo 1698 CCCh., es decir, será el actor quien deberá probar el cumplimiento.

En este sentido, citaremos dos fallos, ambos de la Corte de Apelaciones de Concepción, uno del 28 de diciembre de 2007, rol No 1314-2007, que, en el considerando 40, señala: "Que los presupuestos de las letras a) y c) no han sido desconocidos por las partes, sólo que la demandada en su contestación solicitó el rechazo de la acción por cuanto el demandante no habría pagado, pudiendo hacerlo, la pensión de alimentos decretada en su favor en los últimos años. La ley reconoce al contrayente demandado la posibilidad de enervar la acción de divorcio pidiendo al juez que verifique que el actor durante el cese de la convivencia no ha dado cumplimiento, reiterado, a su obligación en calidad de alimentante. De lo anterior se desprende que la excepción perentoria debe ser alegada por el cónyuge afectado y que el peso de la prueba por aplicación de la regla general del artículo 1698 del Código Civil, corresponde al actor".

El otro, de 27 de mayo de 2008, rol No 1724-2007, en los considerandos $4^{\circ}, 5^{\circ}$ y $6^{\circ}$, expone: " $4^{\circ}[\ldots]$ Ahora bien, durante todo el cese de la convivencia el demandante debe acreditar que ha cancelado la pensión de alimentos a su cónyuge, este cese de la convivencia alcanza el periodo desde que se prueba el cese, en este caso, desde el 11 de mayo de 1999 hasta la eventual sentencia definitiva firme y ejecutoriada que le otorgue el divorcio. Es en este momento que el matrimonio termina, asi lo prescribe el artículo 42 de la Ley de Matrimonio Civil: El matrimonio termina: $4^{\circ}$ por sentencia firme de divorcio $Y$ de acuerdo al articulo 60 de la misma ley, su efectos son que el divorcio pone fin a las obligaciones y derechos de carácter patrimonial cuya titularidad y ejercicio se funda en la existencia del matrimonio, como los derechos sucesorios recíprocos y el derecho de alimentos, exceptuando el pago de la compensación económica que determine la sentencia de divorcio, compensación económica que sus efectos se prolongan más allá de la misma. $5^{\circ}$ Que, en consecuencia, no habiendo acreditado el demandante correspondiéndole el peso de la prueba, que dio cumplimiento -durante el cese de la convivencia- a su obligación de alimentos, sin haber satisfecho dicha obligación hasta el dia de hoy, se debe concluir necesariamente la existencia de su incumplimiento reiterado, de acuerdo al citado artículo 55. $6^{\circ}$ Que arribar a la conclusión contraria, se llegaría ad absurdum, que durante el cese de la convivencia no procedería el pago de pensiones de alimentos lo que no es razonable ni lógico, porque vulnera las obligaciones y deberes derivados de la institución del matrimonio".

2. La conjunción " $y$ ", utilizada por el legislador, sigignifica que el incumplimiento debe darse tanto respecto del cónyuge demandado como de los hijos comunes? 
Afortunadamente, en esta materia, la jurisprudencia ha entendido que es suficiente para enervar la acción de divorcio, el incumplimiento de la obligación alimenticia ya sea en relación con uno u otro(s). Es decir, ha interpretado la norma cumpliendo el mandato del artículo $3^{\circ}$ inciso $1^{\circ} \mathrm{de}$ la Ley No 19.947: "Las materias de familia reguladas por esta ley deberán ser resueltas cuidando proteger siempre el interés superior de los hijos y del cónyuge más débil'.

A vía meramente ejemplar, citaremos las siguientes sentencias:

i) De la Corte de Apelaciones de Concepción, rol No 1314-2007, recientemente mencionada, que, en el considerando 5\%, declara: "Que el inciso tercero del artículo 55 de la Ley $N^{\circ}$ 19.947, previene que no se dará lugar al divorcio si el demandante durante el cese de la convivencia '[...] no ha dado cumplimiento, reiterado, a su obligación de alimentos respecto del cónyuge demandado y de los hijos comunes'. Si bien la norma transcrita emplea la conjunción copulativa 'y', dando a entender que debe haber incumplimiento respecto de ambos alimentarios, la finalidad de la disposición, cual es, sancionar la infracción a la obligación de socorro y el principio de protección al cónyuge más débil, que debe siempre ser respetado en estas materias, conducen necesariamente a concluir que corresponde igualmente desestimar la demanda sea que el incumplimiento haya sido con el cónyuge o con los hijos comunes".

ii) De la Corte de Apelaciones de Chillán, del 7 de diciembre de 2007, rol No 249-2007, que acogió la excepción interpuesta por la demandada, alegando el incumplimiento reiterado del actor en relación con la obligación de alimentos respecto del hijo común.

\section{3. ¿Cuándo se entiende que el incumplimiento de la obligación alimenticia} es reiterado?

Advertimos que la jurisprudencia mayoritaria no ha aplicado la sanción al demandante incumplidor, esto es, no ha acogido la excepción interpuesta por el cónyuge demandado, utilizando argumentos que, en algunos casos, nos parece, contradicen no solo el espíritu de la legislación manifestado en su historia fidedigna, sino, además, el precepto consagrado en el inciso $1^{\circ}$ del artículo 3o de la Ley No 19.947 y, en otros, contravienen la norma expresada en el artículo $2^{\circ}$ transitorio de la misma.

Una sentencia de los tribunales de fondo de Chillán muestra el desacuerdo, entre los jueces, respecto de la posibilidad de enervar la acción de divorcio tanto por el significado que se le otorga al vocablo r e i t e r a d o ocupado por el legislador como por la posibilidad, o no, de considerar incumplimientos acaecidos con anterioridad a la entrada en vigencia de la ley, pues si bien el tribunal de $1^{\mathrm{a}}$ instancia, en causa rol No 2731-2005, acogió la excepción, el de alzada, en causa rol No 600-2006, la rechazó, 
a pesar de haber sido apremiado el demandante en varias oportunidades, argumentando que esta circunstancia no demostraba que los incumplimientos fuesen reiterados. Así, leemos en los considerandos $5^{\circ}$ y 6o: "5o Que de acuerdo a las copias de los expedientes sobre alimentos, del Juzgado de Menores, iniciados en abril de 1979 que rola a fojas 54 y siguientes que en los meses de junio de 1979, octubre de 1980, febrero de 1981, febrero, marzo, mayo, junio y septiembre de 1983 y enero de 1984, el demandado fue objeto de diversos apremios para el pago de la pensión alimenticia. Además en la causa Rol No 66.526 del actual Segundo Juzgado del Crimen de esta ciudad, que rola a fojas 74 y siguientes, también consta que el mismo demandado fue apremiado con arresto en octubre y diciembre de 1998, mayo de 1999 y febrero de 2000, por no pago de pensión alimenticia a su cónyuge y de las copias de la causa RUC 050200304316 del Tribunal de Familia de Chillán, de fojas 119, se desprende que el demandante ha cumplido con el pago de la pensión alimenticia fijada en favor de su cónyuge en forma irregular. 6० Que efectivamente, de acuerdo a lo analizado en el motivo anterior, el actor en algunas oportunidades fue compelido para el pago de la pensión alimenticia a que fue condenado, pero esa circunstancia no demuestra que éste haya incumplido durante el cese de la convivencia en forma reiterada a su obligación del pago de los alimentos, cosa distinta al apremio, razón por la cual no incurriría en la sanción que establece la disposición legal aplicable al efecto".

Llama la atención que los incumplimientos efectivos del actor hayan sido calificados por los jueces como cumplimiento irregular, desestimando, incluso, la existencia de los sucesivos apremios decretados en su contra. Si bien es cierto un apremio no demuestra incumplimiento reiterado, este sí se infiere del hecho de haber sido compelido, el alimentante, en diversas oportunidades contiguas en el tiempo como ocurrió en este caso.

Asimismo, adujo, en el considerando $8^{\circ}$, la supuesta irretroactividad del artículo 55 inciso $3^{\circ}$, por ser una sanción civil: "Que como se ha señalado por la jurisprudencia, la privación de la acción de divorcio vincular, por el no pago reiterado de la obligación de alimentos, durante el cese de la convivencia, es una sanción civil, por lo que no es admisible su aplicación con efecto retroactivo, como consecuencia de lo dispuesto en el artículo $9^{\circ}$ del Código Civil que expresa que 'La ley puede sólo disponer para lo futuro y no tendrá jamás efecto retroactivo'. Asi el eventual incumplimiento reiterado, cuyo no es el caso de autos, puede acarrear otras sanciones civiles, pero no la privación de acción de divorcio, que no puede aplicarse a los actos ejecutados bajo el imperio de la ley antigua, que no la contemplaba”.

Por otra parte, la sentencia de la Corte de Apelaciones de Santiago, de fecha 10 de julio de 2008, rol No 1938-2008, la rechazó, por cuanto la parte demandada la interpuso en el recurso de apelación, estimando que 
ya había caducado el derecho. No obstante, estimamos que la posibilidad de enervar la acción es una excepción perentoria -como lo reconocen, en el considerando $4^{\circ}$, las sentencias de las causas rol № 1314-2007 y rol No 1947-2007, ambas de la Corte de Apelaciones de Concepción-, y, como tal, puede entablarse hasta antes de la vista de la causa en segunda instancia.

La Corte de Apelaciones de Chillán, en la causa antes citada, rol No 249-2007, aplicó la recta doctrina, tanto respecto de la retroactividad, como en relación con el alcance que debe darse al vocablo reiterado, en los considerandos que se indican: " 2 " Que no resulta efectivo que el no pago reiterado de la obligación alimenticia durante el cese de la convivencia, sea una sanción civil carente de efecto retroactivo, ya que la actual Ley de matrimonio civil, que entró en vigencia el 18 de noviembre de 2004, en sus artículos transitorios contempló la situación de los matrimonios contraidos antes de la aplicación de la nueva normativa.I El artículo $2^{\circ}$ transitorio de la Ley 19.947 dispone que los matrimonios celebrados con anterioridad a la entrada en vigencia de esta ley, se regirán por ella en lo relativo a la separación judicial y el divorcio. $3^{\circ}$ Que de la norma transcrita se infiere que la Ley 19.947 no observó el principio recogido en el artículo $3^{\circ}$ de la Ley sobre efecto retroactivo de las leyes en el sentido que el estado civil adquirido y por ende las causales de su extinción se rigen por la ley vigente a la fecha de su constitución. Por consiguiente, todo el régimen de divorcio vincular de la nueva ley, tanto en lo que dice relación con las causales, en cuanto a los titulares de la acción, plazos y requisitos, se aplica a los matrimonios celebrados con anterioridad a su vigencia. $4^{\circ}$ Que por consiguiente, la regla contenida en el artículo $2^{\circ}$ transitorio de la Ley 19.947 asigna efectos inmediatos a la nueva ley y, por ende quienes deseen divorciarse a partir de la entrada en vigor de sus disposiciones, opción ejercida por el actor al presentar su demanda, pueden hacerlo probando que ya tienen el tiempo exigido por la ley y, por su parte, la demandada puede enervar la acción si alega la situación prevista en el inciso $3^{\circ}$ del artículo 55, esto es, que el demandante durante el periodo que media entre el cese efectivo de la convivencia y la demanda, no cumplió reiteradamente con su obligación alimentaria, pudiendo hacerlo".

Por tanto, no dio lugar al divorcio, pues se había despachado apremio en tres oportunidades en contra del demandante, reconociendo la aplicación retroactiva de la ley en esta materia.

Por su parte, la sentencia de la Corte Suprema, del 30 de julio de 2007, rol No 2718-2007, en el considerando $12^{\circ}$, explicita: "Que la regla contenida en el artículo $2^{\circ}$ transitorio de la ley 19.947, asigna efectos inmediatos a la nueva ley y, por ende, quienes deseen divorciarse a partir de la entrada en vigor de sus disposiciones, opción ejercida por el actor al presentar su de- 
manda, pueden hacerlo probando que ya tienen cumplido el tiempo exigido por la ley y, por su parte, los demandados pueden enervar la acción si alegan la situación prevista en el inciso tercero del artículo 55 de la ley $N^{\circ} 19.947$, esto es, que el demandante durante el periodo que media entre el cese efectivo de la convivencia y la demanda, no cumplió reiteradamente con su obligación alimentaria, respecto del cónyuge demandado o los hijos comunes, pudiendo hacerlo". A pesar de ello, desestimó el recurso, por cuanto el recurrente no denunció como conculcadas las reglas de la sana crítica.

El mismo tribunal, con fecha 14 de abril de 2008, en causa rol No 1718-2008, rechazó el recurso de casación en el fondo deducido por la demandada, quien sostenía que los jueces de instancia habían incurrido en error de derecho al resolver que no existían antecedentes claros en el proceso, que acreditaran que el actor hubiese incumplido reiteradamente su obligación, pues no se había decretado apremio en su contra.

Si bien es efectivo que no procedía el recurso de casación en el fondo, pues en los alegatos no se impugnaron los presupuestos fácticos mediante la denuncia de infracción a las normas reguladoras de la prueba, no es menos cierto que los jueces de fondo al requerir la existencia de apremio para acoger la excepción, exigieron más requisitos que los que exige la ley.

En cambio, la Corte de Apelaciones de Concepción, en sentencia del 25 de mayo de 2007, conociendo la causa rol No 13.123 sobre alimentos mayores declara, en su considerando 110: "Que cabe señalar que el artículo 55 inciso $3^{\circ}$, tantas veces mencionado, sólo exige que el actor no haya dado cumplimiento, reiterado, a su obligación de alimentos respecto del cónyuge demandado y de los hijos comunes, pudiendo hacerlo; no siendo necesario, en consecuencia, que se haya decretado algún apremio de los establecidos en la Ley $N^{o} 14.908$ sobre Abandono de familia y pago de pensiones alimenticias. En efecto, cuando la ley ha querido imponer como exigencia previa para un fin determinado la reiteración de apremios, lo ha dicho expresamente, como es el caso del artículo 19 de la Ley 14.908 recién mencionada en que, para decretar las medidas que dicha norma contempla, ha exigido que en el expediente respectivo se hubieren ordenado al menos dos veces alguno de los apremios señalados en el artículo 14 de la citada ley [...]".

Empero, la Corte de Apelaciones de Valdivia, el 20 de mayo de 2008, en causa rol No 1151-2007, confirmó la sentencia del Juzgado de Familia, rit C-514-2006, que no acogió la excepción interpuesta por la demandada alegando el no pago reiterado de las obligaciones alimenticias, aduciendo que el demandante solamente incumplió las pensiones alimenticias para su cónyuge y su hija en el lapso comprendido entre enero de 2005 y abril de 2006.

El término reiterado empleado por el legislador debemos entenderlo 
en su sentido natural y obvio, podemos preguntarnos, entonces, ¿cuándo se cumple con el requisito de la reiteración si dieciséis meses de incumplimiento no se consideran suficientes?

\section{No cabe alegar como petición subsidiaria el cambio de calificación del divorcio.}

En la causa latamente comentada de la Corte de Apelaciones de Chillán, rol No 600-2006, en que el actor demandó divorcio, aduciendo cese efectivo de la convivencia por más de tres años, la cónyuge -como vimosintentó, en primer lugar, enervar la acción alegando el incumplimiento reiterado de la obligación alimenticia y, en subsidio, solicitó que el divorcio se concediese por falta al deber de fidelidad del marido. Los jueces, en el considerando 90, expresan: "Que en cuanto a la petición subsidiaria, esto es, que el divorcio se debió a una falta imputable del demandante, por la causal del $N^{\circ} 2$ del artículo 54 de la Ley No 19.947, toda vez que el actor habría faltado a su obligación de fidelidad, esta pretensión será desestimada, ya que aparte de no estar acreditada, debió haberla hecho valer como acción y no como excepción. Así resulta del artículo 54 de la Ley de matrimonio civil, que dispone que el divorcio podrá ser demandado por uno de los cónyuges, por falta imputable al otro cónyuge, siempre que constituya una violación grave de los deberes y obligaciones que les imponía el matrimonio, que torne intolerable la vida en común".

5. No procede solicitar indemnización por daño moral, sino respecto del divorcio culpa, y ello en sede ordinaria por delito o cuasidelito civi $\mathbb{R}^{\circ}$, aunque es más dudoso, en demanda reconvencional.

Un fallo de la Corte de Apelaciones de Rancagua, del 29 de octubre de 2007, rol No 672-2007, negó a la demandada la indemnización por daño moral solicitada por los sufrimientos ocasionados por el cese de la convivencia, indicando, en el considerando 30: "Cabe señalar que este rubro no lo contempla la Ley 19.947, razón suficiente para que sea rechazado su pago tanto más si en la especie no se dio ni se dará lugar al divorcio por la causal culposa invocada por aquella. La extrapolación que pretende la apelante del pago del daño moral en los términos que señala el artículo 2329 del Código Civil al ámbito de familia, no resulta pertinente, puesto que, situado dicho

\footnotetext{
${ }^{2}$ VIDAL, Álvaro, La compensación por menoscabo económico en la Ley de matrimonio civil, en VIDAL, Álvaro (coordinador), El nuevo Derecho chileno del matrimonio (Santiago, Editorial Jurídica de Chile, 2006), p. 287, sostiene: "que la compensación económica no excluye el ejercicio de la acción indemnizatoria por el daño por delito o cuasidelito civil derivado de los hechos constitutivos de las causales de divorcio del artículo 54 de la Ley de Matrimonio Civil”.
} 
pago solo en el ámbito extracontractual, recientemente se ha extendido a la responsabilidad contractual, integración que aún no alcanza a aquellas situaciones que por el cese de la vida en común puedan afectar seriamente a uno $o$ a ambos cónyuges recíprocamente, y que impliquen aquellos sufrimientos a que se refiere el apelante".

Uno de los efectos del matrimonio, en relación con los cónyuges, es el derecho-deber de convivencia, salvo, dice el legislador, que a alguno de ellos le asista razones graves para no hacerlo, artículo 133 CCCh. Surge, entonces, la siguiente interrogante, ¿̨habría cambiado la resolución de los jueces en el caso que la demandante reconvencional, en vez de alegar la infidelidad del actor -que no acreditó- hubiese aducido infracción grave al derecho-deber de convivencia sin que hubiese razones de peso que justificasen la ausencia? Pensamos que habrían tenido que acogerla, por cuanto, en el No 2 del artículo 54, el legislador consagra esta causal del divorcio culpa.

\section{6. ¿El cese efectivo de la convivencia significa separación de techo?}

En otra oportunidad ${ }^{3}$, nos referíamos al significado que la legislación argentina le atribuye al cese efectivo de la convivencia y, en especial, a si es requisito sine qua non para que se configure, la separación de techo. Luego de un acabado análisis, concluíamos que lo fundamental para su determinación no es el lugar donde residan los cónyuges, sino la existencia, o no, del animus separationis. Así, bien puede un matrimonio decidir separarse $\mathrm{y}$, por motivos económicos o por el bien de los hijos, continuar viviendo bajo el mismo techo sin ánimo de hacer vida marital.

Nuestro legislador, en relación con la reanudación de la vida en común establece la necesidad de que se realice con ánimo de permanencia, por ende, es dable inferir que, en los casos en que esta intención no exista, estaremos frente a un cese efectivo de la convivencia.

Nuestra jurisprudencia confirma que el hecho de continuar viviendo bajo el mismo techo, siempre que haya cesado la affectio, no obsta para desechar una demanda, o una solicitud de divorcio, basada en el cese de la convivencia, como lo podemos apreciar en los considerandos $7^{\circ}$ y $8^{\circ}$ de la sentencia ya aludida de la Corte de Apelaciones de Concepción, rol No 1724-2007: "7o Que el cese de la convivencia, como se dijo, fue a partir del 11 de mayo de 1999, de acuerdo al documento de fs. 198, fiel a su original según certificación notarial de fs. 202 vta. y que corresponde al comparendo celebrado entre las partes en el Primer Juzgado Civil de Talcahuano, causa

${ }^{3}$ Quintana Villar, María Soledad, La separación y el divorcio, cit. (n. 1), pp. 79-80. 
rol $N^{\circ} 2.786-99$, sobre violencia intrafamiliar, donde deciden separarse de hecho, y considerando que ambos no tienen otro lugar donde vivir, acordaron hacerlo en la misma casa habitación pero, en dormitorios separados. $8^{\circ}$ Que no es necesario para el cese de la convivencia el corpus separationis, sino la no subsistencia de la affectio, requisito que caracteriza la intensión de no hacer vida en común, lo que ha sucedido en el caso sub judice, aun cuando convivan los cónyuges bajo un mismo techo".

\section{INTERPOSICIÓN CONJUNTA DE LA SOLICITUD DE DIVORCIO CONSENSUAL}

Tampoco ha sido pacífica la interpretación de los jueces respecto de la voz solicitan utilizada por el legislador en relación con el divorcio de común acuerdo. El inciso $1^{\circ}$ del artículo 55 de la Ley No 19.947 prescribe: "Sin perjuicio de lo anterior, el divorcio será decretado por el juez si ambos cónyuges lo solicitan de común acuerdo y acreditan que cesado su convivencia durante un lapso mayor de un año". Basándose en el significado del verbo solicitar, un mismo abogado patrocinó a ambos cónyuges en un tribunal con competencia en materias de familia de Concepción. Habiéndose elevado en consulta, rol No 3189-2005, la Corte de Apelaciones de esta ciudad, el 16 de enero de 2006, resolvió anular todo lo obrado, reponiendo la causa al estado en que cada parte designase su propio abogado y mandatario judicial. El voto de la mayoría señala, en los considerandos $2^{\circ}$ y $3^{\circ}$ : "2० Que de acuerdo al artículo $4^{\circ}$ del Código de Procedimiento Civil, toda persona que deba comparecer en juicio a su propio nombre o como representante legal de otra, deberá hacerlo en la forma que determine la ley. Esta ley es la 18.120, que en su artículo $1^{\circ}$ prescribe que la primera presentación de cada parte $o$ interesado en asuntos contenciosos o no contenciosos ante cualquier tribunal de la República, sea ordinario, arbitral o especial, deberá ser patrocinado por un abogado habilitado para el ejercicio de la profesión. $3^{\circ}$ Cabe agregar, por otra parte, que el hecho que un mismo abogado patrocine a las dos partes de un pleito, es constitutivo de un delito especifico, el contemplado en el artículo 232 del Código Penal [...]".

A nuestro parecer, la recta doctrina la encontramos en el voto de minoría de don René Ramos Pazos, quien declara: "La situación regulada en la disposición legal recién citada-artículo 55 inciso 10-, no tiene el carácter de juicio, siendo su naturaleza jurídica la de una gestión no contenciosa, por cumplir la doble exigencia establecida en el artículo 817 del Código de Procedimiento Civil, esto es, requiere la intervención del juez y no existe controversia entre partes". 


\section{LEGITIMADOS ACTIVOS PARA ENTABLAR LA ACCIÓN DE NULIDAD}

Pero no solo en materia de divorcio encontramos jurisprudencia contradictoria, también en otra causal de término del matrimonio, la nulidad y respecto de los legitimados activos para entablar la acción.

El artículo 46 de la Ley de matrimonio civil consagra la regla general en relación con esta materia -son sujetos activos para demandar la nulidad del matrimonio, cualesquiera de los presuntos cónyuges- $y$, a continuación, enumera las excepciones.

A pesar de ser el legislador claro al respecto, ha sido mal interpretado en algunos fallos que han rechazado la demanda de nulidad presentada por el bígamo, aplicando el principio general "nemo auditur propria turpitudinem allegans", establecido en el artículo 1683 CCCh.

Así, la Corte de Apelaciones de Concepción, con fecha 21 de abril de 2008, en la causa rol No 2193-2007, revocó la sentencia de primera instancia aduciendo que el demandante habría carecido de titularidad para alegar la nulidad de su segundo matrimonio, puesto que ejecutó el acto sabiendo o debiendo saber el vicio que lo invalidaba, concordando en este punto con el informe de la segunda fiscalía judicial, pero discordando con él, respecto de la procedencia de declarar la nulidad de oficio, pues "[...] el vicio que justifica la declaración de nulidad absoluta de oficio o por iniciativa del tribunal, debe hallarse presente, patentizarse, saltar a la vista en el instrumento mismo que da constancia del acto o contrato que se juzga y que esto no ocurre cuando el vicio emerge de la relación que existe entre ese instrumento y otros elementos probatorios, como sucede en la especie, ya que la nulidad del matrimonio que se reclama no salta a la vista al examinar el certificado y acta que dan cuenta de su celebración con otros elementos probatorios, en razón de lo cual esta Corte no concuerda con la opinión de la Fiscal Judicial, de declarar de oficio la nulidad del matrimonio impetrada".

Sin embargo, la ley enumera taxativamente las excepciones a la regla general y, respecto del impedimento de ligamen, prescribe: "La acción de nulidad fundada en la existencia de un vinculo matrimonial no disuelto corresponde, también, al cónyuge anterior o a sus herederos". Por tanto, no excluye al cónyuge bígamo como lo reafirma el término ta mbién.

Es preciso señalar que, rigiendo la Ley de matrimonio civil de 1884, una sentencia de la Corte de Apelaciones de Santiago, de fecha 30 de julio de 2002, rol No 8526-2001, aplicó correctamente la ley, desestimando la aplicación del artículo 1683 CCCh., por cuanto "[...] las limitaciones que en estos preceptos se contienen para ejercer acción de nulidad, como lo es la prevista en el artículo 1683 respecto de quienes sabian o debian saber del vicio de nulidad que invalidaba el acto, no deben hacerse extensivas al ejercicio 
de la acción de nulidad de un contrato de matrimonio, regida por normas legales especiales que no impiden impetrarla a cualquiera de los cónyuges, aun concurriendo dicha circunstancia".

\section{POSIBILIDAD DE INVOCAR EN SEDE CIVIL LA DECLARACIÓN DE NULIDAD ECLESIÁSTICA DE MATRIMONIO}

Como es sabido, el legislador canónico ha ejercido cierta influencia en el legislador civil, como se aprecia en los nuevos capítulos de nulidad ${ }^{4}$. En efecto, el canon 1095 del Código de Derecho Canónico fue acogido, con solo algunos leves matices diferenciadores, en el artículo 5 números 3 y 4 de la Ley No 19.947.

El año 2006 se presentó en el 6º Juzgado Civil de Santiago, una demanda de nulidad de matrimonio, argumentándose haber sido declarada la nulidad en sede eclesiástica "[...] por adolecer de las causales de nulidad dispuestas en el No 2 del canon 1095 y, de modo subsidiario, en el $N^{o} 3$ del mismo canon, sentencia que ha adquirido el carácter de firme, desde el 15 de julio de 2003. Se dice en la demanda reconvencional, que es la que contiene esta pretensión, que estos vicios son igualmente aplicables, en virtud de lo dispuesto en los artículos 44 y $45 N^{\circ} 3$ y 4 LMC. al matrimonio civil realizado entre ambos, desde que el matrimonio religioso y civil se celebraron en fechas cercanas. La incapacidad que afectaba a la demandante de autos existía también al tiempo de contraerse matrimonio civil'.

La Corte de Apelaciones, en causa rol No 5453-2006, confirmó la sentencia de $1^{\mathrm{a}}$ instancia, desestimando los recursos de casación en la forma y de apelación interpuestos en su contra, aun reconociendo la similitud de las causales, por cuanto "[...] para que pueda ser acogida una acción de nulidad, en los términos de la nueva normativa legal, resulta también de toda evidencia que la o las causales que se invoquen deben ser probadas por medio de las evidencias consagradas en el Código de Procedimiento en lo civil, sin que baste el mero hecho de que haya existido una nulidad eclesiástica, como se ha planteado, aunque se base en las mismas causales que en el presente juicio se han invocado. Desde luego, hay que precisar que no resulta prueba suficiente la copia de la sentencia dictada en sede eclesiástica, o aun una copia del juicio completo, ya que en el presente caso sólo tiene la calidad de un documento y en el evento de que pudiere otorgársele la calidad de documento o instrumento público, cabe recordar que al tenor del artículo 1700 del Código Civil: El instrumento público hace plena fe en cuanto al hecho de haberse otorgado y su fecha, pero no en cuanto a la verdad de las declaraciones que en él hayan

${ }^{4}$ Sobre esto: Quintana Villar, María Soledad, La nulidad matrimonial, en El nuevo Derecho chileno del matrimonio, cit. (n. 2), pp. 193-215. 
hecho los interesados. En esta parte no hace plena fe sino contra los declarantes. Por lo tanto, y en estricto rigor, en el presente juicio debió probarse, adecuadamente, el fundamento de la nulidad alegada, y como ello no se hizo, la demanda reconvencional no ha tenido posibilidades de prosperar, habiendo sido atinadamente desechada".

Nos parece acertada la resolución de ambos tribunales, por cuanto si bien se había declarado la nulidad eclesiástica por causales recogidas por el legislador de la Ley No 19.947, no podemos desconocer la autonomía existente entre una y otra sede.

\section{APLICACIÓN JURISPRUDENCIAL DE LA COMPENSACIÓN ECONÓMICA}

La institución de la compensación económica, establecida por la actual Ley de matrimonio civil, ha sido analizada por los juristas ${ }^{5}$ y ampliamente alegada por los abogados, sin embargo, en la mayoría de los casos, podemos percibir desconocimiento respecto de su naturaleza jurídica, sus requisitos de procedencia y la necesidad de acreditarlos.

En estas breves líneas, no intentaremos hacer doctrina respecto de la compensación económica, sino, a partir del análisis jurisprudencial, mostrar diversos problemas en relación con su aplicación.

1. Respecto de la obligación de informar acerca de la existencia de la compensación económica.

El artículo 64 inciso 2o establece: "Si no se solicitare en la demanda, el juez informará a los cónyuges la existencia de este derecho durante la audiencia de conciliación".

En general, los tribunales de justicia han cumplido con este deber y es digno de resaltar que cuando lo han omitido los magistrados, han suplido su silencio otros funcionarios del poder judicial. Este el caso del fallo rol No 260-2008, de la Corte de Apelaciones de Iquique, de fecha 12 de mayo de 2008, que, conociendo de una consulta, señala: "Visto y oído: Con fecha 23 de abril ppdo. (fojas 7), don Teddy Thompson Cáceres, Jefe Administrativo de Causas del Tribunal de Familia de Iquique, certificó que

${ }^{5}$ A vía ejemplar, señalamos, VidAl Olivares, Álvaro, en VIDAL, Álvaro (coordinador), El nuevo Derecho chileno del matrimonio, cit. (n. 2), pp. 193-287; BARRIENTOS Grandón, Javier - Novales Alquézar, Aranzazú, Nuevo Derecho matrimonial chileno (Santiago, 2004), pp. 401-432; López Díaz, Carlos, Manual de Derecho de familia y tribunales de familia (Santiago, 2005), pp. 291-300; Pizarro WiLson, Carlos, La compensación económica en la nueva Ley de Matrimonio Civil, en Revista Chilena de Derecho Privado 3 (2004), pp. 83-104. 
habiendo escuchado el audio de la presente causa, no hay constancia en él de haberse dado información a las partes sobre la compensación económica contemplada en la Ley de matrimonio civil [...]. 5० Que hay que dejar asentado que si bien, como se señaló, la señora Juez no hizo una advertencia formal del derecho a la compensación económica, que en este caso debería haberse efectuado a la demandante, de los antecedentes aportados al juicio no se divisa que el demandado esté en condiciones de efectuar algún aporte económico, lo que la demandante tampoco pretende pues incluso se desistió de la petición de alimentos por las hijas comunes, interesándole únicamente el divorcio. $6^{\circ}$ Que, en el articulo 25 de la Ley $N^{\circ}$ 19.968, que crea los Tribunales de Familia, se reglamenta la nulidad procesal para los procedimientos de esta especialidad, y se establece como requisito esencial para su procedencia la existencia de perjuicio para las partes. En el caso sub lite se aprecia que la única parte que podría resultar perjudicada con la infracción cometida por la señora juez de familia, al no dar cumplimiento al artículo 64 de la Ley de matrimonio civil, sería la cónyuge demandante, pero atento a su situación personal y familiar, le resultaría más perjudicial la casación del presente juicio, por una cuestión meramente formal, para obtener una eventual declaración de un hipotético derecho que en la práctica no se podrá concretar por lo que esta Corte no hará uso de la facultad de invalidar de oficio".

Así, no obstante la existencia del vicio, se resolvió no casar de oficio la sentencia, pues habría resultado perjudicial para ambas partes.

\section{En relación con su naturaleza jurídica.}

Este tema ha sido discutido por la doctrina, existiendo diversas teorías al respecto.

a) La compensación económica no es una sanción. En la sentencia de la Corte Suprema del 28 de noviembre de 2007, rol No 1787-2007, en el considerando $24^{\circ}$, se reproduce la argumentación del abogado de la parte demandada, de la cual podemos colegir -como lo hizo el tribunal- que este consideraba la compensación económica, una sanción: "Que por su parte el apoderado de la demandada principal señala que la compensación económica es un tema nuevo, por lo que cabe preguntarse, por qué procede. No son alimentos, pero es consecuencia o producto que alguno de los cónynges, al cumplir sus deberes sufrió un menoscabo económico, no se pudo desarrollar profesionalmente [...] resulta legitimo que aquello que no se hizo durante la vigencia del matrimonio se haga después, por eso se debe favorecer al cónyuge que está saliendo perjudicado. Su proyección previsional garantiza sólo una pensión minima, porque no se le pagaron las imposiciones. El matrimonio duró 11 años de convivencia, ella fue buena madre, y la ley dice que si ella se dedicó a su hogar, se le debe compensar; agrega el abogado que la 
ley no quiere que la gente se divorcie entonces, si se da esta situación, surge la compensación económica, esto es porque ocurrió una irregularidad en el curso normal de los acontecimientos. Se debe devolver al cónyuge que le permitió al otro tener el desarrollo profesional, pero cuánto valdrá ese sacrificio [...]".

La magistrada descarta la posibilidad de considerar la compensación económica una sanción, expresando, en el considerando 40": "Que esta sentenciadora tampoco está de acuerdo con los fundamentos del abogado de la demandada, ya que entender la compensación económica como una especie de castigo para el matrimonio que se separa, es atribuir al derecho un rol sancionador en el ámbito de la familia, desconociendo que, precisamente los cambios sociales han permitido constatar que esta es una de las áreas más sensibles de tales transformaciones, profundas y significativas, cambios que por lo demás no son punibles. El divorcio o la separación conyugal son hechos humanos $y$ sociales que no se pueden evitar o impedir por simples decretos o leyes; luego atribuirle al derecho el carácter de contralor respecto de las relaciones humanas $y$ sociales es desnaturalizar su esencia, es desconocer su actuación post factum y finalmente es un argumento que se aparta del contenido fundamental de la norma en cuestión. La voluntad del legislador es contribuir a la justicia entre los cónyuges [...]".

b) La compensación económica no es una pensión alimenticia. En los considerandos $3^{\circ}$ y $4^{\circ}$ de una sentencia de la Corte de Apelaciones de Concepción, de fecha 20 de mayo de 2008, rol No 24992007, los ministros señalan que la compensación económica no puede transformarse en una suerte de pensión alimenticia, por lo que cabe la posibilidad de condenar al pago de compensación económica, aun cuando el obligado, durante la vigencia del matrimonio, hubiese desembolsado fuertes sumas de dinero por concepto de alimentos, siempre que exista menoscabo económico originado por las causas señaladas por la Ley de matrimonio civil: "3o Que no está demás señalar que para la fijación de la compensación económica se pueden utilizar todas las alternativas que hagan posible su cumplimiento, pero en ningún caso ella puede transformarse en una especie de pensión alimenticia. $4^{\circ}$ Que, por lo mismo, no puede confundirse una compensación económica derivada del término del matrimonio con una pensión alimenticia, porque si bien el demandado reconvencional paga una importante cantidad de dinero por este último concepto, ella no es óbice para fijar una compensación económica de acuerdo con el menoscabo que efectivamente sufrió la demandante reconvencional'.

En el mismo sentido, la Corte Suprema, en causa rol No 21-2008, del 16 de enero del año en curso, en su considerando $19^{\circ}$, reproduciendo la sentencia de primera instancia que confirma, explicita: "Que la naturaleza jurídica de la compensación económica en Chile no tiene un carácter alimenti- 
cio, sino más bien encuentra su fundamento en el carácter resarcitorio de ciertos perjuicios ocasionados por la dedicación al cuidado de los hijos y a las labores del hogar común, y que principalmente se relacionen con las pérdidas económicas derivadas de no haber podido, durante el matrimonio, dedicarse uno de los cónyuges a una actividad remunerada, o haberlo hecho en menor medida de lo que podia y quería y de los perjuicios derivados del costo de oportunidad laboral que se refiere a las proyecciones de vida laboral futura".

c) La compensación económica no tiene carácter indemnizatorio. El Tribunal de Familia de Pudahuel, en causa rit C-1061-2006, conociendo de un divorcio, en su considerando 7o, determina: “[...] En cuanto a la compensación económica, ella no tiene un carácter indemnizatorio; por tal motivo es requisito para concederla no solo que el cónyuge se haya dedicado al cuidado de los hijos, sino que como consecuencia de ese cuidado y de las labores del hogar común, el cónyuge de que se trata, no haya desarrollado actividad lucrativa o haya visto menoscabadas las posibilidades de obtener un mejor ingreso monetario [...]".

Por su parte, la Corte Suprema en causa rol No 1787-2007, del 28 de noviembre de 2007, en el considerando $1^{\circ}$, señala: "[...] es dable colegir que la compensación económica no constituye una indemnización a todo evento por el solo hecho de decretarse el divorcio".

En otro fallo, este mismo tribunal, en causa rol No 53-2008 del 24 de marzo del presente año, expresa: "La compensación por menoscabo económico consiste en el derecho que asiste a uno de los cónyuges, cuando por haberse dedicado al cuidado de los hijos o a las labores propias del hogar, no pudo durante el matrimonio desarrollar una actividad lucrativa o lo hizo en menor medida de lo que podía o quería, con el fin de que se le compense el menoscabo económico que, producido por el divorcio o la nulidad sufrirá por esta causa. El cónyuge que pretende esta compensación debe solicitarla en la oportunidad procesal pertinente y acreditar en autos los supuestos que la hacen procedente. Se trata de una acción cuyo objeto es el reconocimiento del derecho a ser resarcido por el menoscabo padecido por haberse dedicado a las labores del hogar común y al cuidado de los hijos en el caso correspondiente. Por consiguiente, no basta con probar la dedicación a los hijos y/o a las labores del hogar, sino que es necesario acreditar, además, la circunstancia de haber estado el cónyuge que la demanda en condiciones ciertas de desarrollar una actividad remunerada".

Leemos, finalmente, en el considerando $11^{\circ}$ de la sentencia de la Corte de Apelaciones de Concepción, rol No 1865-2006, dictada con fecha 28 de noviembre de 2006: "Que la compensación económica consiste en el derecho que asiste a uno de los cónyuges, normalmente la mujer, cuando por haberse dedicado al cuidado de los hijos o a las labores propias del hogar, 
no pudo durante el matrimonio desarrollar una actividad remunerada o lucrativa, o lo hizo en menor medida de lo que podia y quería, para que se le compense por el menoscabo económico que, producido el divorcio o la nulidad, sufrirá por esta causa". Luego, en el considerando 140, expone: "Que 'no debe atribuirse a la compensación económica consagrada en la ley, un carácter alimenticio o indemnizatorio, no obstante que presente algunos rasgos comunes o semejantes y, lo que se pretende reparar es, en todo caso, una pérdida patrimonial y no moral./ Se ha dicho y resuelto que se pretende cubrir, por un lado el desequilibrio económico entre los cónyuges que impide a uno enfrentar la vida futura de modo independiente y, por otro, el costo de oportunidad laboral, esto es, la imposibilidad o disminución de inserción en la vida laboral que el cónyuge ha experimentado por haberse dedicado a la familia. Este costo, podría asimilarse a la idea del lucro cesante, pero solamente por aproximación, porque no apunta a lo que se ha dejado de obtener, sino una oportunidad de obtener que es distinto'(Carmen Domínguez Hidalgo, La Compensación económica en la Ley de matrimonio civil, Colegio de Abogados, página 13; esta Corte, Revista de Legislación y Jurisprudencia, Leyes y Sentencias, No 24, página 25)”.

Advertimos que la postura, al parecer, mayoritaria, entiende la compensación económica como un mecanismo legislativo que tiene por objeto subsanar una situación de menoscabo económico entre los excónyuges, originado en los presupuestos que la ley establece.

\section{Respecto del requisito del menoscabo económico.}

Mientras el artículo 61 de la Ley de matrimonio civil entrega los supuestos necesarios para que se considere que existe un menoscabo económico $\mathrm{y}$, consecuencialmente, la procedencia de una compensación económica, el artículo 62 enumera elementos que, a vía ejemplar, pueden ser utilizados para determinar la cuantía de dicho detrimento. En relación con estos temas apreciamos que algunos magistrados han efectuado una verdadera labor docente, pues, si bien, en casi todas las sentencias analizadas, observamos desconocimiento de los abogados de cara a los requisitos de la institución en comento, principalmente, en lo referente a la existencia, o no, de detrimento económico, esta ignorancia ha sido suplida por los jueces.

a) ¿Qué se entiende por menoscabo económico? Aquí también -como respecto de la naturaleza jurídica de la compensación económicaexisten opiniones diversas.

i) Es un daño. Así lo estima la sentencia antes citada del Tribunal de Familia de Pudahuel, rit C-1061-2006, en el considerando 7o, segunda parte, que señala: "[...] El objeto de la compensación es restaurar un daño 
o menoscabo que pudo tener el cónyuge a causa del matrimonio y evitar una situación de indefensión al término de este".

En el mismo sentido, la Corte Suprema, en el considerando $18^{\circ} \mathrm{de}$ la causa rol No 21-2008, del 16 de enero de 2008, anteriormente mencionada, indica: "[...] Que además de la situación de desigualdad, ésta debe dar lugar a un menoscabo económico, perjuicio o daño cuya causa inmediata es la propia ruptura matrimonial, lo que quiere decir es que sin la frustración del proyecto común de vida que el matrimonio implica tal menoscabo no se hubiera producido [...]".

ii) Es un efecto patrimonial. Como lo leemos en el considerando $11^{\circ} \mathrm{de}$ un fallo ya aludido de la Corte Suprema, causa rol No 1787-2007: "Que otro requisito esencial para la procedencia de la compensación económica constituye la existencia del menoscabo económico [...]. La ley no define el concepto, pero la interpretación armónica de los artículos de la ley 19.947, permite concluir que se trata del efecto patrimonial que se produce en el cónyuge que no pudo trabajar o lo hizo en menor medida de lo que podía o quería".

iii) Es un desequilibrio económico. Tesis utilizada por la Corte de Apelaciones de Concepción, con fecha 3 de abril de 2008, en causa rol No 1947-2007, en el considerando 17o: "Que de la historia del establecimiento de la ley y de la opinión de los autores nacionales, aparece que el menoscabo económico es el desequilibrio o disparidad económica entre los cónyuges tras la terminación del matrimonio para enfrentar sus vidas separadas en el futuro".

La controversia respecto de la naturaleza del menoscabo no es solo jurisprudencial como podemos apreciar en un fallo de la Corte de Apelaciones de Valparaíso del 10 de abril de 2008, rol No 2856-2007, que cita a diversos autores en su considerando $4^{\circ}$ : "[...] se debe tener presente que la Ley no define el concepto de 'menoscabo económico', para lo cual tanto la doctrina como la jurisprudencia han realizado esfuerzos por determinar su significación, para algunos no se trata de daños, sino de 'un desequilibrio o disparidad económica entre los dos cónyuges, un obstáculo para que ambos hagan su vida separada en un plano de igualdad' (profesor Vidal Olivares, 'El nuevo derecho matrimonial chileno', Editorial Jurídica de Chile, 2006), en cambio para otros, para que el juez pueda conceder el beneficio 'se debe acreditar en el proceso el referido menoscabo, cuando se produce el retiro del estatuto protector del matrimonio derivado del divorcio' (profesor Corral Talciani, Revista Chilena de Derecho, Vol. 34 No 1, pp. 23-40, 2007) y, finalmente también se estima que el menoscabo económico es 'un desequilibrio o desventaja, que la compensación viene en corregir' (profesor Andreucci Aguilera). Como se advierte de todo lo consignado hay un elemento común, cual es el detrimento, menoscabo económico que se produce a uno de 
los cónyuges con motivo del divorcio [...] estableciendo para ello un remedio que impide su empobrecimiento al término del contrato de matrimonio, cual es el corregir la situación de menoscabo producida a propósito del rol desempeñado, que no tiene la naturaleza jurídica de una pensión alimenticia, sino de una indemnización por la pérdida legitima de derechos u opciones sufridos en comparación con el otro cónyuge".

b) Época en la que debe ocurrir el menoscabo. Existe, asimismo, un problema de interpretación en lo que dice relación con la época en la que debe ocurrir dicho menoscabo, como observamos en el considerando $18^{\circ}$ de la causa rol No 21-2008, ya citada, de la Corte Suprema, que señala: "[...] del análisis del artículo 31 y siguientes de la ley No 19.947, es posible reconocer ciertas condiciones objetivas básicas que precisa el ordenamiento jurídico para que nazca el derecho a poder exigir el devengo de la compensación económica, tales como, en $1^{\circ}$ lugar la existencia de matrimonio [...]. En $2^{\circ}$ lugar, la concurrencia a la fecha de la ruptura matrimonial de una situación de desequilibrio apreciada tanto en el plano subjetivo (posición de un cónyuge respecto de la del otro) como temporal (comparando la situación existente al momento mismo de la ruptura matrimonial con la que presumiblemente sea la posición futura (tras la separación o el divorcio). Las situaciones a comparar radican entre los momentos inmediatamente anteriores y posteriores a la ruptura de la convivencia, siendo intrascendentes, en orden a la detección de ese inicial desequilibrio económico requerido por la norma jurídica, las circunstancias de bonanza o pobreza vividas por los cónyuges antaño o las que se pudieran producir hasta la declaración judicial del divorcio. No existen, pues, varios momentos para detectar el desequilibrio que requiere la norma jurídica, sino tan sólo uno, el inmediatamente anterior y posterior a la ruptura de la convivencia of fracaso matrimonial'.

4. La prueba en relación con los requisitos de la compensación económica.

Los principales problemas para acoger una demanda de compensación económica, derivan de la probanza de sus requisitos de procedencia.

Se ha solicitado la compensación económica, a veces, sin mayor sustento que la argumentación del abogado y, en otras oportunidades, presentando medios probatorios insuficientes como lo podemos apreciar en las siguientes sentencias. Así, el considerando $16^{\circ}$ de la causa rol No 1947-2007, previamente citada, explicita: "[...] puede concluirse que no basta con que concurra el supuesto típico de la compensación, sino que es esencial el tercer elemento constitutivo, esto es, el menoscabo económico, que no se presume, es necesaria su prueba, incluida la de las circunstancias que, a titulo ejemplar, enumera el artículo 62".

Por su parte, se lee en el considerando $22^{\circ}$ de la sentencia de la Corte de 
Apelaciones de Concepción, del 20 de mayo de 2008, rol No 2499-2007: "Que la demanda de compensación económica [...] requiere la concurrencia de los requisitos establecidos en el considerando vigésimo, los que no se consideran acreditados en la causa de marras con la prueba rendida, pues ellos no permiten determinar a este Magistrado un menoscabo real y efectivo, ni la imposibilidad total o parcial de desarrollar actividad remunerada a consecuencia de que se dedicó al cuidado de los hijos o a las labores propias del hogar común".

Podemos advertir el criterio de la Corte Suprema, a este respecto, en diversos fallos, que pasamos a citar:

i) Rol No 5048-2006, del 12 de marzo de 2007, que, en su considerando 12', señala: "Que, no obstante manifestar durante la audiencia de fojas 26 y 27 su oposición a la demanda de divorcio, el demandado no ha acreditado suficientemente los hechos y no obstante ello y en subsidio demanda compensación económica. Durante el juicio la demandada no aportó probanza alguna sobre la cual apoyar los fundamentos de su oposición".

ii) Rol No 4428-2007, del 10 de octubre de 2007, que, expresa en el considerando 70 "[...] En cuanto a la compensación económica [...] de los antecedentes de la causa no aparece que la demandante recibiría menoscabo económico a consecuencia del divorcio y si bien es cierto que ella no desempeñó actividad remunerada durante parte del tiempo que este duró, esta fue de corta duración no más de tres años, hecho que no fue controvertido por las partes en su demanda reconvencional. Por tanto, no ha lugar a la demanda reconvencional'.

iii) Rol No 1787-2007, del 28 de noviembre de 2007, que, en el considerando $28^{\circ}$, declara: "Que dado que en materia probatoria es posible acreditar los hechos positivos, ninguno de los dichos expuestos por los testigos previamente mencionados resultan concluyentes para tener por acreditada la existencia de causales legales al tenor de lo que establece el artículo 61 ya citado, ni de los hechos a probar contenidos en el motivo 14 de esta sentencia".

iv) Rol No 21-2008, del 16 de enero de 2008, que rechaza la demanda reconvencional de compensación económica de acuerdo con los argumentos aducidos en los considerandos que se indican: " $21^{\circ}$ Que a mayor abundamiento, los testigos de la parte demandada principal no se encuentran contestes en que aquella haya solventado en exclusivo los gastos de mantenimiento del hogar común. 22० Que por lo demás no se ha rendido prueba alguna tendiente a establecer la cuantía de estas prestaciones, en el evento de haber tenido lugar". 


\section{CONCLUSIONES}

En las conclusiones de uno de los artículos anteriormente menciona$\operatorname{dos}^{6}$, me refería a la peculiar contradicción que se manifiesta en la Ley No 19.947, pues aunque el legislador trató latamente la nulidad matrimonial, incorporando capítulos provenientes de la legislación canónica, previó, sin embargo, que se preferiría, para poner término al matrimonio, la nueva causal, esto es, el divorcio vincular, en atención a que la probanza de sus requisitos, por lo menos, en dos de sus vertientes, es simple en contraposición con la dificultad que representa acreditar la configuración de la mayoría de las causales de nulidad.

Hemos comprobado, a través del análisis de sentencias relativas a estas causales de término del matrimonio, que mientras las demandas de nulidad son muy escasas en relación con las de divorcio basadas en el cese de la convivencia, casi no existe diferencia, en cuanto al número, respecto de las de divorcio culpa. La razón es evidente, en el divorcio remedio y en el consensual, basta verificar el cese de la convivencia, en cambio, en las de nulidad y divorcio culpa, es necesario probar la causal invocada.

En la praxis, es indubitado que, para aquel que quiere poner término unilateralmente a su matrimonio, le conviene alegar el cese de la convivencia por el lapso exigido, pues, hemos podido comprobar que la única excepción capaz de enervar la acción de divorcio, raramente ha sido acogida.

Para terminar, quisiéramos destacar que, si bien la mayoría de los magistrados ha cumplido la obligación de comunicar la existencia de la compensación económica y, asimismo, ha aleccionado a muchos abogados a su respecto, frecuentemente se ha adoptado una posición restrictiva en su aplicación, en cambio, como señalábamos recientemente, en lo que se refiere a las demandas de divorcio remedio o unilateral, se ha actuado de manera condescendiente, concediéndolo, no obstante la configuración de la excepción mencionada.

[Recibido el 6 y aprobado el 15 de noviembre de 2008].

\section{BIBLIOGRAFÍA}

Barrientos Grandón, Javier - Novales Alquézar, Aranzazú, Nuevo Derecho Matrimonial Chileno (Santiago, LexisNexis, 2004).

${ }^{6}$ Quintana Villar, María Soledad, La nulidad matrimonial, en El nuevo Derecho chileno del matrimonio, en VIDAL, Álvaro (coordinador), El nuevo Derecho chileno del matrimonio (Santiago, Editorial Jurídica de Chile, 2006), p. 215. 
López Díaz, Carlos, Manual de Derecho de familia y tribunales de familia (Santiago, Editorial Librotecnia, 2005).

PIZARRO WiLSON, Carlos, en La compensación económica en la nueva Ley de matrimonio civil, en Revista Chilena de Derecho Privado 3 (2004).

QuinTANA VILlar, María Soledad, La nulidad matrimonial, en El nuevo Derecho chileno del matrimonio (Santiago, Editorial Jurídica de Chile, 2006).

QUINTANA VILLAR, María Soledad, La separación y el divorcio en la Ley de matrimonio civil, en GuZmán Brito, Alejandro (editor científico), Colección de estudios de Derecho civil en Homenaje a la profesora Inés Pardo de Carvallo (Valparaíso, Ediciones Universitarias de Valparaíso, 2008).

Vidal Olivares, Álvaro, La compensación por menoscabo económico en la Ley de matrimonio civil, en El Nuevo Derecho chileno del matrimonio (Santiago, Editorial Jurídica de Chile, 2006). 